\title{
Daniel Zöller
}

\section{Die Zinsbereinigte Gewinnsteuer (ZGS)}

Steuersystematische Entwicklung und ökonomische Analyse eines Reformvorschlags für Deutschland

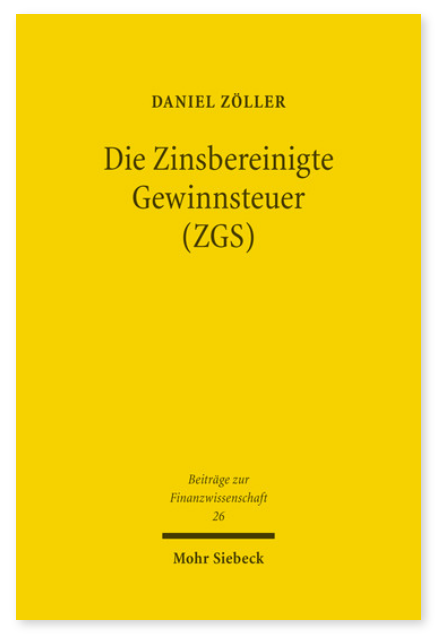

2011. XIV, 268 Seiten. BtrFin 26

ISBN 978-3-16-151076-2

DOI 10.1628/978-3-16-151076-2 eBook PDF $74,00 €$

ISBN 978-3-16-150671-0

fadengeheftete Broschur 74,00€
Mit der Zinsbereinigten Gewinnsteuer entwickelt Daniel Zöller einen Reformvorschlag, der trotz enger politischer und internationaler Restriktionen Finanzierungs-, Investitions- und Rechtsformneutralität sicherzustellen vermag. Die steuersystematisch konsistente Ausarbeitung des ZGS-Steuersystems erstreckt sich über die Einkommen- und Körperschaftsteuer bis zur Gewerbesteuer als Bestandteil eines schlüssigen Gemeindesteuersystems. Als zweite kommunale Ertragsteuer sollen die Gemeinden mittelfristig eine kommunale Bürgersteuer mit Hebesatzrecht erhalten. In einem erweiterten neoklassischen Wachstumsmodell weist der Autor positive Wachstumseffekte und das Erreichen einer langfristig optimalen intertemporalen Kapitalallokation nach. Im Unterschied zu rein konsumorientierten Steuersystemen erzielt die ZGS dabei Aufkommen aus der Kapitaleinkommensbesteuerung. Die Modellanalyse zeigt zudem Vorteile des ZGS-Systems im Vergleich zu zwei aktuellen Vorschlägen für eine Duale Einkommensteuer auf.

Daniel Zöller Geboren 1979; Studium der Volkswirtschaftslehre in Heidelberg; Wissenschaftlicher Mitarbeiter an der Forschungsstelle »Marktorientiertes Steuersystem« des Alfred-Weber-Instituts für Wirtschaftswissenschaften der Universität Heidelberg; 2010 Promotion; seit 2009 Mitarbeiter bei einer großen Steuerberatungs- und Wirtschaftsprüfungsgesellschaft in Stuttgart.
Jetzt bestellen:

https://mohrsiebeck.com/buch/die-zinsbereinigte-gewinnsteuer-zgs-9783161510762?no_cache=1

order@mohrsiebeck.com

Telefon: +49 (0)7071-923-17

Telefax: +49 (0)7071-51104 